\title{
Utilization of Sodium Acetate by Shigella and Escherichia
}

\author{
By I. D. COSTIN \\ State Inspection for Hygiene, Enterobacteria Laboratory, \\ Timişoara, Rumania
}

(Received 16 February 1965)

\begin{abstract}
SUMMARY
The chemically defined medium with sodium acetate as sole carbon source (sodium acetate agar) devised by Trabulsi \& Ewing (1962) was used to examine 414 strains of Shigella and 446 strains of Escherichia. None of the 414 Shigella cultures (belonging to the subgroups, A, B, C, D) utilized acetate and did not develop on sodium acetate agar, whereas about $95 \%$ of 283 anaerogenic and non-motile and all 163 aerogenic Escherichia isolates studied, utilized sodium acetate and grew on sodium acetate agar. It is concluded that the utilization of acetate on sodium acetate agar has a definite value for the differentiation of strains of the genera Shigella and Escherichia.
\end{abstract}

\section{INTRODUCTION}

Between the Shigella and Escherichia groups, as now defined (Ewing \& Edwards, 1962 ; Edwards \& Ewing, 1962; Carpenter, $1963 a$ ) there is a wide spectrum of relationships, expressed also through an appreciable genetic homology (Luria \& Burrows, 1957; Stenzel, 1961; Falkow, Schneider, Baron \& Formal, 1963; Stenzel, 1963; Stenzel \& Meier, 1964) as well as through biochemical and antigenic similarities (Ewing, Hucks \& Taylor, 1952; Ewing, 1953; Ewing, Tatum, Davis \& Reavis, 1956; Ewing, Reavis \& Davis, 1958; Edwards \& Ewing, 1962). As the procedures for the determination of genetic compatibilities are not included among those used in most diagnostic laboratories, and pathogenic properties are not internationally accepted as taxonomic criteria for the groups of the family Enterobacteriaceae (Carpenter, 1963b), the positive and differential diagnosis of Shigella and Escherichia (as of all other groups of the family) is based on biochemical and antigenic tests; for group determination biochemical characters are used predominantly. With Shigella and Escherichia, of the 41 serotypes accepted in the Shigella group, only 5 do not exhibit relationships with the $O$ (1-145) antigens of the Escherichia group; 14 Shigella serotypes have identical $O$ antigens with that of some Escherichia types, and the remaining 24 serotypes of Shigella present different degrees of antigenic relationships of the type a-a, b or a, b-a, c with the members of the Escherichia group (Edwards \& Ewing, 1962). It is evident that biochemical tests have particular value in the examination of isolates which might belong to one of these groups. There is no difficulty in the recognition of 'typical' Escherichia strains (prompt lactose fermentation, motility, aerogenesis) which are most frequently encountered, but the identification of slow lactose-fermenting (24 $\mathrm{hr}$ or more) non-motile and anaerogenic strains which conform to Shigella and Escherichia definitions after the usual biochemical screening tests is sometimes difficult. 
Up to September 1962 we used for the separation of the lactose non-fermenting, non-motile and anaerogenic strains which for the rest conformed to the Shigella and Escherichia groups, the tests for lysine and ornithine decarboxylation, Christensen's citrate, sodium mucate and the decomposition of several carbohydrates. In September 1962 we were informed, through the courtesy of Dr W. H. Ewing (Atlanta, Georgia, U.S.A., who kindly supplied the manuscript of a then unpublished paper) about a chemically defined medium containing sodium acetate as sole carbon source, which Trabulsi \& Ewing (1962) had found valuable in the differentiation of Shigella and Escherichia cultures. From that date we used this test in our routine biochemical tests for the examination of Enterobacteriaceae. The present paper reports the results obtained with this test of sodium acetate utilization in the differentiation of Shigella and Escherichia strains.

\section{METHODS}

Organisms. Between September 1962 and January 1965, 860 isolates which were found to belong to Shigella and Escherichia were tested for their ability to utilize acetate. With some few exceptions, all the strains studied had been freshly isolated

Table 1. Shigella serotypes tested on sodium acetate agar

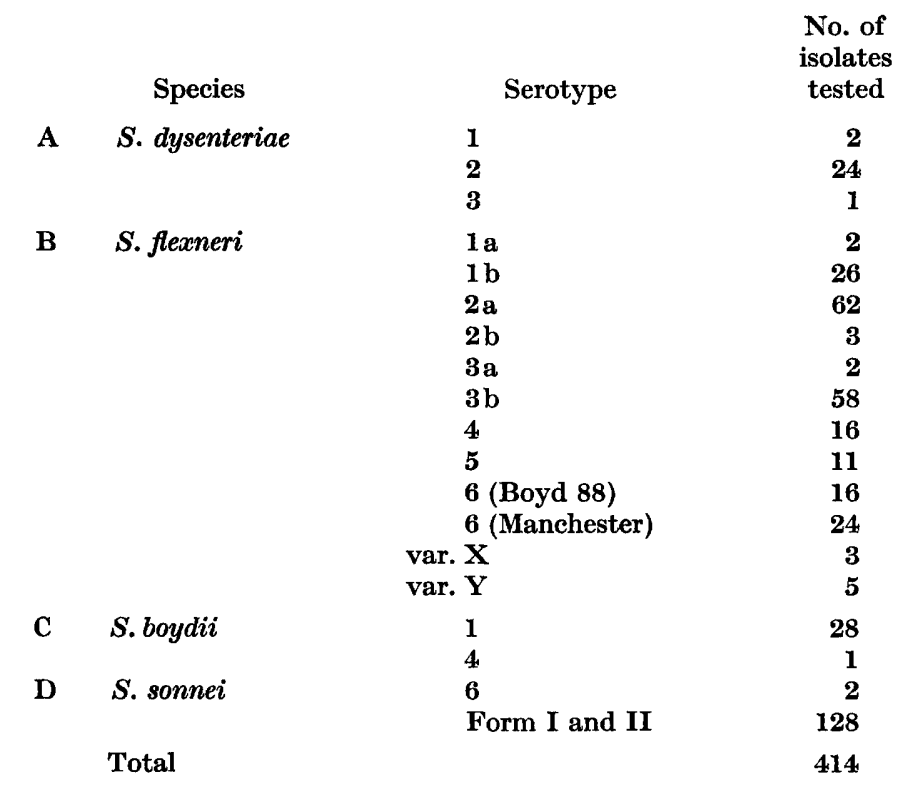

from stools of diarrhoeal and non-diarrhoeal persons, who were being examined for diagnostic or prophylactic purposes. The identification of these isolates was made biochemically and serologically (not all cultures) according to internationally accepted procedures (Report, 1958; Edwards \& Ewing, 1962). Other technical details about the biochemical methods were given elsewhere (Costin, 1965). The Shigella strains belonged to the subgroups B, D, C, A (in decreasing numerical frequency; see Table 1). 
Medium. The sodium acetate agar medium (SAA) was prepared according to Trabulsi \& Ewing (1962): distilled water, $100 \mathrm{ml}$.; $\mathrm{NaCl}, 0.5 \mathrm{~g}$.; $\mathrm{MgSO}_{4} . \mathbf{7} \mathrm{H}_{2} \mathrm{O}, 0.02 \mathrm{~g}$. ; $\mathrm{NH}_{4} \mathrm{H}_{2} \mathrm{PO}_{4}, 0 \cdot 1$ g.; $\mathrm{K}_{2} \mathrm{HPO}_{4}, 0 \cdot 1$ g.; sodium acetate $0 \cdot 2$ g.; agar (washed 3 days), $2 \cdot 0 \mathrm{~g}$; ; bromthymol blue (1/500) aqueous solution), $4 \mathrm{ml}$.

The ingredients were dissolved by boiling, the agar added, and the solution adjusted

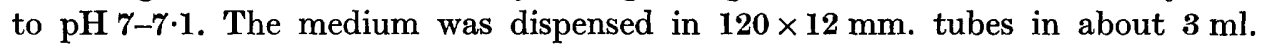
amounts, the tubes closed with rubber stoppers, autoclaved for $15 \mathrm{~min}$. at $121^{\circ}$ and cooled in a sloped position to form a butt of about $10 \mathrm{~mm}$. The tubes were inoculated over the surface of the slopes with saline suspensions from fresh $(20 \mathrm{hr})$ agar cultures and incubated at $37^{\circ}$ for 7 days. Readings were made daily. Since it was noticed that correct results were obtained only when there was some syneresis liquid in the bottom of the tubes, only such tubes were used. In all instances, in which nonlactose-fermenting, anaerogenic and non-motile strains were examined, other significant biochemical tests (lysine and ornithine decarboxylation, Christensen's citrate, sodium mucate, carbohydrates) were also done; beginning in 1963, the $\beta$-galactosidase test (Le Minor \& Ben Hamida, 1962) was also used.

\section{RESULTS}

Table 2 summarizes the results obtained; none of the 414 Shigella isolates used acetate as sole carbon source in the presence of inorganic nitrogen, and did not develop on the sodium acetate agar (SAA) during the 7 days of observation.

Table 2. Groroth of some Shigella, Escherichia and Salmonella cultures on sodium acetate medium

\begin{tabular}{|c|c|c|c|c|c|c|}
\hline \multirow[b]{3}{*}{ Group (serotype) } & \multirow{3}{*}{$\begin{array}{l}\text { No. of } \\
\text { strains } \\
\text { tested }\end{array}$} & \multicolumn{3}{|c|}{ No. of positive strains in } & \multirow{2}{*}{\multicolumn{2}{|c|}{$\%$}} \\
\hline & & & & & & \\
\hline & & 1 day & 2 days & days & + & - \\
\hline Shigella $(A, B, C, D)$ & 414 & & & & & 100 \\
\hline $\begin{array}{l}\text { E. coli (lactose non-fermenting, non- } \\
\text { motile, anaerogenic, serologically } \\
\text { undetermined) }\end{array}$ & 169 & 134 & 22 & 4 & 94.7 & $\mathbf{5 \cdot 3}$ \\
\hline $\begin{array}{l}\text { E. coli (belonging to Alcalescens- } \\
\text { Dispar) }\end{array}$ & 114 & 103 & $\mathbf{5}$ & 1 & $95 \cdot 6$ & 4.4 \\
\hline $\begin{array}{l}E \text {. coli (lactose non-fermenting/24 hr/ } \\
\text { aerogenic) }\end{array}$ & 68 & 65 & 3 & - & 100 & . \\
\hline E. coli (prompt lactose-fermenting) & 57 & 57 & $\cdot$ & . & 100 & . \\
\hline E. coli 124: $72\left(\mathrm{~B}_{17}\right)$ & 37 & 22 & 13 & 2 & 100 & . \\
\hline E. coli 112 ac: $66\left(B_{11}\right)$ & 1 & $\mathbf{1}$ & . & . & . & . \\
\hline Salmonella typhi & 10 & - & . & • & . & 100 \\
\hline S. gallinarum and S. pullorum & 602 & & . & . & & 100 \\
\hline Other Salmonella (B-group) & 34 & 34 & . & . & 100 & 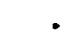 \\
\hline
\end{tabular}

From the 169 strains of lactose non-fermenting ( $<24 \mathrm{hr}$ ), non-motile and anaerogenic Escherichia coli, which did not belong to alkalescens-dispar, 124:72 and 112ac:66 serotypes, and which were not further identified serologically, 94.7\% developed and made alkaline the SAA medium, mostly after $24 \mathrm{hr}$ incubation.

A similar proportion of positive results (95.6\%) was obtained with 114 Escherichia strains, which were biochemically similar to the above collection but which 
belonged to 0 (1-8) A-D antigens (mostly to $0_{1}$ ). In the case of the strains from the above two collections which did not grow on SAA (5.3 and $4 \cdot 4 \%$, respectively) the diagnosis of Escherichia was established on the ground of positive results in one or more of the significant biochemical tests (lysine, ornithine, mucate, Christensen's citrate) and confirmed serologically by lack of significant reaction with the Shigella antisera. We encountered no strain which was positive on SAA and negative in all the other above-mentioned significant biochemical tests. In no instance, therefore, was the diagnosis of Escherichia established only on a positive result in the SAA test. Further, the SAA test was positive with all the 68 motile and aerogenic, slow lactose-fermenting Escherichia strains tested and also with all the other 57 prompt lactose-fermenting Escherichia strains originating from diarrhoeal cases, which belonged to certain determined 0 -antigen groups and which were described previously (Costin, 1964).

Thirty-seven Escherichia coli 124:72 strains from those so far tested utilized acetate (see also Costin \& Olinici, 1965); similarly one strain of E. coli 112ac:66.

From the results obtained with the sodium acetate agar test in other groups of Enterobacteriaceae, only those of some Salmonella strains are included in Table 1 for comparison; the strains of Salmonella gallinarum-pullorum were all of avian origin (see Costin et al. 1964).

\section{DISCUSSION}

The fact that none of the 414 Shigella strains examined developed on the sodium acetate agar (SAA) medium, seems to indicate that the inability to use acetate as sole carbon source in the presence of inorganic nitrogen in a chemically defined medium is a constant feature of members of the Shigella group. Though many of the accepted Shigella serotypes were not represented in our material, yet the agreement of the results presented here with those reported by Trabulsi \& Ewing (1962) is strong support for the conclusion that a culture which is able to develop on SAA medium can be excluded from the Shigella group, as at present defined. The high proportion of positive results (growth on SAA medium) obtained with the nonmotile, anaerogenic and lactose non-fermenting Escherichia coli strains, which are easily mistaken for Shigella strains, especially in view of the antigenic relationships mentioned in the Introduction, shows the usefulness of the SAA medium for differentiating these Escherichia variants from true Shigellas. Such $E$. coli variants (belonging or not to the specified A-D antigenic groups) are not rare in the material encountered in routine work. Thus, in the period September 1962 to January 1965, we encountered 283 such strains, representing about $4 \%$ of all strains of lactosenegative (24 hr) Enterobacteriaceae isolated by us from faeces mostly from nondiarrhoeal subjects. Since about $5 \%$ of the anaerogenic Escherichia isolates gave negative results with SAA, it is evident that the acetate utilization test cannot be recommended as a sole differentiating test between Shigella and Escherichia. The results of the work reported here show that the acetate utilization in the SAA medium of Trabulsi \& Ewing (1962) is useful for the differentiation of the members of the Shigella and Escherichia groups. Therefore, it may be said that any taxonomical study of strains called 'intermediate' between Shigella and Escherichia is incomplete (Ewing \& Edwards, 1962), if there is no mention of results obtained with the sodium acetate utilization test. 
The writer wishes to acknowledge his indebtedness to Dr W. H. Ewing, Atlanta, Georgia, for the courtesy of having supplied the manuscript on SAA medium before its publication.

\section{REFERENCES}

Carpenter, K. P. (1963a). Report of the Subcommittee on Taxonomy of the Enterobacteriaceae. Int. Bull. bact. Nomencl. Taxon, 13, 69.

Carpenter, K. P. (1963b). Minutes of Enterobacteriaceae Subcommittee meeting, Montreal, August 1962. Int. Bull. bact. Nomencl. Taxon, 13, 139.

Costris, I. D. (1964). Maladies diarrhéiques chez enfants et adultes associées à Escherichia coli n'appartenant pas aux sérotypes dits entéropathogènes. Budapest, 4th Congress Microbiology.

Costin, I. D. (1965). Bemerkungen zur Praxis der biochemischen Identifizierung der Darmbakterien in der Routinearbeit. Zentbl. Bakt ParasitKde I. Ref. 198, 289.

Costin, I. D. \& OuInicr, N. (1965). Studiul unor tulpini de Escherichia coli serotip 124:72 $\left(\mathrm{B}_{19}\right)$, izolate de la copii şi adulţi cu enterite. Microbiologia Parazit. Epidem. 10, 49.

Costin, I. D., Petrica, L., Gariou, M., Onica, P., Pelle, A. \& Dinu, N. (1964). Correlation between origin and biochemical behaviour of Salmonella gallinarum and Salmonella pullorum cultures. Zentbl. Bakt. ParasitKde I. Orig. 194, 342.

EDWARDS, P. R. \& Ewing, W. H. (1962). Identification of Enterobacteriaceae, 2nd edition. Minneapolis: Burgess Publishing Comp.

Ewrng, W. H. (1953). Serological relationships between Shigella and coliform cultures. J. Bact. 66, 338.

Ewing, W. H. \& EDwards, P. R. (1962). The Principal Divisions and Groups of Enterobacteriaceae and their Differentiation. Atlanta, Georgia, U.S.A.: Communicable Diseases Center Publication.

Ewing, W. H., Hucks, M. C. \& Taylor, M. W. (1952). Interrelationships of certain Shigella and Escherichia cultures. J. Bact. 63, 319.

Ewing, W. H., Reavis, R. W. \& Davis, B. R. (1958). Provisional Shigella serotypes. Can. J. Microbiol. 4, 89.

Ewing, W. H., Tatum, H. W. Davis, B. R. \& Reavis, R. W. (1956). Studies on the Serology of the Escherichia coli Group. Atlanta, Georgia, U.S.A.: Communicable Diseases Centre Publication.

Falkow, S., Schnemer, H., Baron, L. S. \& Formal, S. B. (1963). Virulence of Escherichia-Shigella genetic hybrids for the guinea pig. J. Bact. 86, 1251.

Le Minor, L. \& Ben Hamida, F. (1962). Avantages de la recherche de la $\beta$-galactosidase sur celle de la fermentation du lactose en milieu complexe, dans le diagnostic bactériologique en particulier des Enterobacteriaceae. Ann. Inst. Pasteur, 102, 267.

LurIA, S. E. \& Burrous, J. W. (1957). Hybridization between Escherichia coli and Shigella. J. Bact. 74, 461.

Report of the Enterobacteriaceae Subcommittee of the Nomenclature Committee of the International Association of Microbiological Societies, 1958. Int. Bull. bact. Nomencl. Taxon 8, 25.

STENzEL, W. (1961). Escherichia coli-Shigella-Hybriden und ihre Schleimhautpathogenitat. Z. Hyg. InfektKrankh. 147, 521.

STENzEL, W. (1963). Untersuchungen über die Hybridisierung zwischen $E$. coli und Shigella in vivo. Arch. Hyg. Bakt, 147, 444.

Stenzel, W. \& Merer, R. (1964). Experimentall-genetische Untersuchungen zur Frage einer Motilitätsübertragung auf unbewegliche Typen der Coli-Shigella-Gruppe. Arch. Hyg. Bakt. 148, 475.

Trabulsi, L. R. \& Ewing, W. H. (1962). Sodium acetate medium for the differentiation of Shigella and Escherichia cultures. Publ. Hlth Lab. 20, 137. 